\title{
Surface topography after deep rolling with milling kinematics
}

\author{
Berend Denkena $^{1} \cdot$ Alexander Krödel $^{1} \cdot$ Steffen Heikebrügge ${ }^{1} \cdot$ Kolja Meyer $^{1}$ (D) $\cdot$ Philipp Pillkahn $^{1}$
}

Received: 21 September 2020 / Accepted: 8 February 2021 / Published online: 19 February 2021

(c) The Author(s) 2021

\begin{abstract}
Deep rolling is a machining process which is used to decrease roughness and to induce compressive residual stresses into component surfaces. A recent publication of this research group showed possibilities to predict the topography during deep rolling of bars in a lathe. Although deep rolling can be used in a milling machine to machine flat specimens, it is still unclear, whether the topography can be predicted to a similar extend using this application. To investigate the influence of the machining parameters on topography, three experimental stages are performed in this paper on cast AlSi10Mg. First, single-track deep rolling experiments are performed under variation of the deep rolling pressure $p_{w}$ to find the relationship between $p_{w}$ and the indentation geometry. Here, a logarithmic relationship between deep rolling pressure and the indentation characteristics could be found that achieved a relatively high agreement. In the second stage, surfaces are prepared using multi-track deep rolling. Here, the deep rolling pressure $p_{w}$ and the lateral displacement $a_{b}$ are varied. The multi-track rolled surfaces were compared to an analytical model for the calculation of the theoretical roughness that is based on the logarithmic relationship found in the first experimental stage. Here, the limits of the analytical prediction were shown because high similarities between predicted and measured surfaces only occurred for certain deep rolling pressures $p_{w}$ and lateral displacements $a_{b}$. To further investigate the limitations of this procedure, a novel tool concept, which utilizes the rotation of the machine spindle, is used in the third stage. Here, the generated surface can also be interpreted as a periodic sequence of spheric indentations as shown in the second experimental stage, whereas the measured surfaces differed from the expected surfaces. As a result of this paper, the predictability of the surface topography after deep rolling of flat specimens is known (minimum pressure $p_{w, \operatorname{minAlSi} i 0 \mathrm{Mg}}=5 \mathrm{MPa}$ and minimum lateral displacement $a_{b, \operatorname{minAlSi} 10 \mathrm{Mg}}=0.25 \mathrm{~mm}$ ) and also first results regarding the final topography after using the novel tool concept are presented.
\end{abstract}

Keywords Surface integrity $\cdot$ Roughness $\cdot$ Topography $\cdot$ Deep rolling $\cdot$ Burnishing

\section{Introduction}

Deep rolling is a machining process which is commonly used to improve the surface integrity of metallic components. It is usually applied after cutting processes like turning for axisymmetric workpieces or milling for flat workpieces. Deep rolling can be performed using different tool concepts and the force can be applied using mechanical (i.e. spring loaded) or hydrostatic mechanisms. The tool can have a spherical, cylindrical or torical shape. While mechanical tools provide the possibility to use the deep rolling device without further machine modifications, hydrostatic tools

Kolja Meyer

meyer_k@ifw.uni-hannover.de

1 Institute for Production Engineering and Machine Tools, Leibniz University Hannover, Garbsen, Germany offer the possibility to provide continuous deep rolling forces when machining free-form or unround workpieces. When using hydrostatic tools, an additional hydrostatic compressor system is necessary. In this paper, processes with hydrostatic force application and spherical tools are used [1]. Accordingly, only these processes are discussed in this introduction. The influence of the deep rolling parameters on the roughness of the axisymmetric workpieces is well described.

Courbon et al. investigate the influence of various deep rolling parameter combinations on the roughness of $27 \mathrm{MnCr} 5$ workpieces. They observe that the feed $\mathrm{f}$ and the deep rolling pressure $p_{w}$ influence the roughness Ra and $\mathrm{Rz}$ [2]. Meyer et al. use deep rolling to machine metastable austenitic steels. Here, the resulting roughness $\mathrm{Ra}$ and $\mathrm{Rz}$ mainly depends on the ball diameter $d_{b}$ and the mechanical properties induced by different heat treatments. The deep rolling pressure $p_{w}$ plays a minor role and the feed $\mathrm{f}$ is not 
varied [3]. Schuh et al. achieve a similar result when machining Ti6Al7Nb. Roughness is reduced with increasing deep rolling pressure $p_{w}$ until a sufficient deformation is achieved. A reduction of feed $f$ and an increase of the ball diameter $d_{b}$ lead to a roughness reduction [4]. Mader describes the deep rolling process as a sequence of aligned embossing [5]. Denkena et al. use this description for a geometric model of the topography after deep rolling. If a sufficient mechanical load is applied, topography can be predicted by a geometric calculation under consideration of the ball diameter $d_{b}$ and the feed $\mathrm{f}$. The mechanical load is described by $Q_{\text {def }}$, which is the relationship between maximum Hertzian pressure $p_{\max }$ and the yield strength $R_{p 0.2}$ [6]. The process limits for AISI1045, AISI4140 and Al6082 are shown in Fig. 1. For the applicability of the model a minimum of $Q_{\text {def }} \approx 7$ is necessary. The model is also limited by the feed f. If $Q_{\text {def }}>10$ is achieved, the maximum feed for an applicability is increased to $f_{\max }=0.3 \mathrm{~mm}$. This is indicated by the yellow area in Fig. 1. No upper boundary for $Q_{d e f}$ and the applicability of the model was found. However, with increasing $Q_{\text {def }}$ disruptions of the surfaces can appear. The detailed information about the test execution can be found in the paper of Denkena et al. [6]. If the surface is not fully deformed because of a workpiece material with high mechanical strength [7] or low deep rolling forces, a roughness prediction model has to include the initial roughness and the experimentally determined indentation geometry [8].

The use of hydrostatic tools on flat workpieces is uncommon, compared to the machining of round workpieces. One possible reason for this fact is, that the machining time increases with the comparably low feed velocities $v_{f}$ which can be offered by milling centers. Therefore, deep rolling of flat workpieces is usually performed with mechanical tools which include cylindrical roller elements and use the spindle

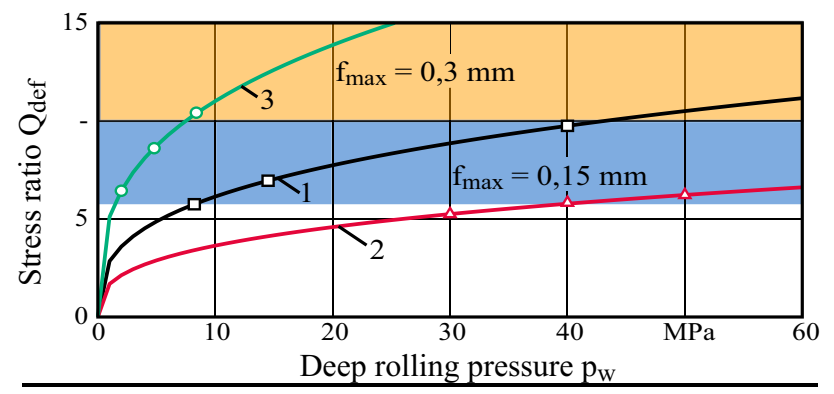

$\begin{array}{ll}\text { Deep rolling } & \text { Material } \\ \text { Workpiece diameter: } & 1: \text { AISI1045 } \\ \mathrm{d}_{\mathrm{W}}=59 \mathrm{~mm} & 2: \text { AISI4140 QT } \\ \text { Ball diameter: } & 3: \text { Al6082 } \\ \mathrm{d}_{\mathrm{b}}=6,35 \mathrm{~mm} & \end{array}$



My/93332 CIFW

Fig. 1 Influence of material and deep rolling pressure on the application of the model [6] rotation [9]. Deep rolling with milling-like kinematics and hydrostatic tools is only performed on geometrically complex and cost intensive workpieces such as fan blades $[5,10]$. The current situation can be summarized as follows:

- Surface topography after deep rolling with turning kinematics is predictable under certain conditions. Here, the relationship between mechanical load and yield strength $Q_{\text {def }}$ is important.

- Deep rolling of flat and free-form samples is possible by using a milling machine.

- The machining of flat specimens takes a long time when using a single-track tool with spherical shape. In stateof-the-art hydrostatic approaches, the spindle rotation is not used.

- Spring loaded deep rolling systems can provide an uneven machining load when machining rough or free-form geometries, because slight deviations can cause a deep rolling force difference. Using this approach, the prediction of surface parameters is therefore complex.

These facts lead to the conclusion that a new hydrostatic deep rolling tool which obtains the spindle rotation must be developed to increase productivity when deep rolling with milling-like kinematics. Besides the construction and application of such a tool concept, a first approach regarding surface topography prediction should be applied. Therefore, the goal of this paper is the prediction of surface topography after deep rolling with milling kinematics. To achieve this goal, the following steps are performed:

1. Determination of the indentation geometry in singletrack experiments.

2. Variation of the lateral displacement $a_{b}$ in multi-track experiments.

3. Development of a multi-spherical deep rolling tool with milling kinematics.

4. Experimental evaluation of the resulting geometry.

\section{Materials and methods}

The experiments are conducted in three stages. During the first and second experimental stage, a single mounted standard ECOROLL HG6 deep rolling tool with an external compressor system is used. In the first stage, single-track deep rolling experiments under variation of the deep rolling pressure $p_{w}$ are performed. Here, the indentation geometry is evaluated to investigate the influence of the indentation depth and width to prepare the subsequent experiments. In the second stage, samples are deep rolled under variation of the lateral displacement $a_{b}$. Subsequently surface topography is evaluated to investigate, under which condition its 
Table 1 Mechanical properties of AlSi10Mg [11]

\begin{tabular}{lll}
\hline Material & Yield strength $R_{p 0.2}$ & Tensile strength $R_{m}$ \\
\hline AlSi10Mg & $180 \mathrm{MPa}$ & $220 \mathrm{MPa}$ \\
Poisson & Hardness ratio & \\
0.35 & $75 \mathrm{HB}$ & \\
\hline
\end{tabular}

prognosis is possible. In the third stage, a new tool concept which utilizes milling kinematics is used and the resulting surface topography is evaluated. All experiments are conducted using continuously cast AlSi10Mg, which is cut into squared slices with a height of $8 \mathrm{~mm}$ and with a side length of $80 \mathrm{~mm}$. The mechanical properties of this material are listed in Table 1.

For the basic investigations during the first and second experimental stage, a standard single-mounted ECOROLL HG6 deep rolling tool with an external compressor system is used. The ball diameter of a HG6 tool is $d_{b}=6.35 \mathrm{~mm}$ and the external compressor can provide a deep rolling pressure of $p_{w}=2-60 \mathrm{MPa}$. In the first experimental stage, the pressure is varied between $p_{w}=2$ and $10 \mathrm{MPa}$ in steps of $1 \mathrm{MPa}$. The stress relationship $Q_{\text {def }}$ is calculated according to Denkena et al. [6] by application of Hertzian contact between a sphere and a flat specimen after Johnson [12]. The stress relationship ranges between $Q_{\text {def }}(2 \mathrm{MPa})=9.45$ and $Q_{\text {def }}(10 \mathrm{MPa})=16.2$. It can therefore be assumed that a sufficient degree of deformation is achieved throughout all experiments. Each experiment is performed thrice. In the second experimental stage, the lateral displacement is varied in five stages of $a_{b}=0.05,0.11,0.25,0.4,0.5 \mathrm{~mm}$ and the deep rolling pressure is varied in three stages $p_{w}=2,5,8$ $\mathrm{MPa}$. For the third experimental stage, a new tool design is used. As depicted in Fig. 2a), the tool consists of a standard HSK100 tool taper with an adapter/holder which holds two ECOROLL HG6 rolling elements. The elements are placed in a radial distance of $d_{t o o l}=27 \mathrm{~mm}$. The adapter consists of two joined parts with milled channels for fluid transport. During these experiments, the deep rolling pressure $p_{w}$ is applied by using the coolant pressure system of the milling center. For all experiments, a Heller H5000 milling center is used, because this machine tool can apply a nominal fluid pressure of $p_{w, n o m}=10 \mathrm{MPa}$, of which $p_{w, \max }=8 \mathrm{MPa}$ arrive at the tool due to the systematic losses of the pressure system. Every hydraulic compressor system generates losses due to tube friction, throttles and vessels. In the novel milling kinematic tool, the taper, the adapter and the rolling element contain such loss generators. This results in a reduction of the fluid pressure provided by the machine tool $\left(p_{w, n o m}\right)$ to a fluid pressure at the rolling ball $\left(p_{w, \max }\right)$. For the determination and validation of $p_{w, \max }$ in-process force measurements have been conducted. The tool has a millinglike process kinematic, where the tool is set to rotation and a) Milling kinematic tool

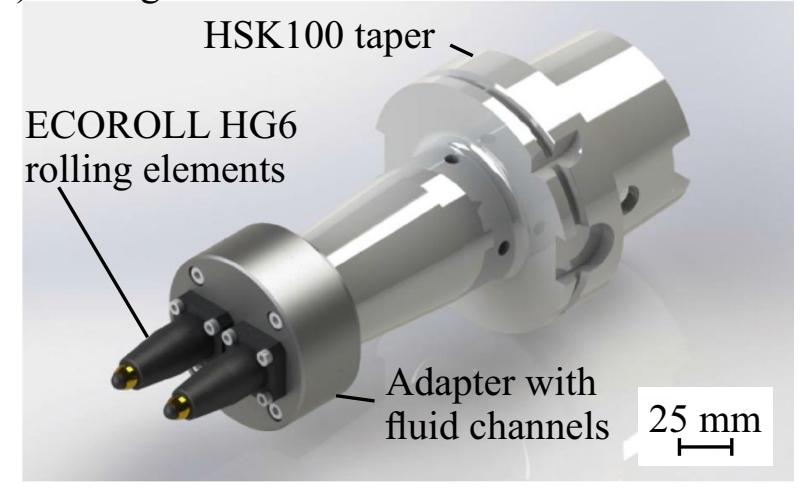

b) Process kinematics

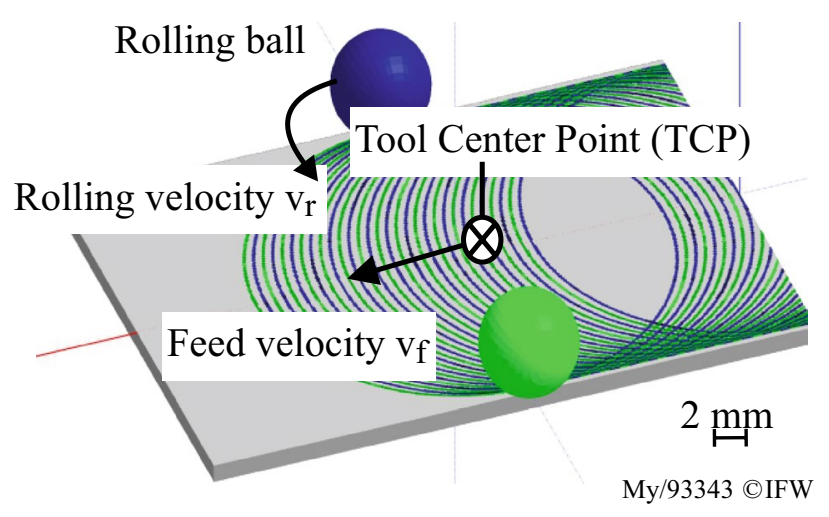

Fig. 2 Tool design and path of the milling kinematic deep rolling tool

the machining is performed by a linear movement to the machining axis. As shown in Fig. 2b), this process kinematic leads to the depicted tool path. Here, the distance between the tracks differs depending on the rotational angle $\phi$. With increasing $\phi$, the number of contacts or, depending on the relationship between feed $\mathrm{f}$ and indentation width $w_{i}$, the distance between deep rolling induced grooves decreases. The smallest distance is achieved for $\phi=90^{\circ}$. In the ranges between $\phi=0^{\circ}$ and $\phi=90^{\circ}$ the deep rolling paths are crossing, resulting in a new rolling of the previous rolled surface by the running after ball. One single experiment with a rotational speed of $\mathrm{n}=50 \mathrm{~min}^{-1}$ and a feed per rolling element of $f_{b}=0.25 \mathrm{~mm}$ is performed.

\section{Results}

The goal of the first experimental set is to gain information on the load dependent indentation geometry. Here, both, the indentation width $w_{i}$ and the indentation depth $d_{i}$ are relevant, as they can limit the validity of a geometric indentation model. Figure 3 shows a tactile measurement through the tracks generated with a pressure of $p_{w}=6 \mathrm{MPa}$. It is visible that all indentations are similar regarding indentation depth 




\section{Deep Rolling:}

Single-Track

Pressure:

Lat. displacement: $\mathrm{a}_{\mathrm{b}}=0$ Workpiece:
Ecoroll HG6

$\mathrm{d}_{\mathrm{b}}=6.35 \mathrm{~mm}$

Ceramic

AlSi10Mg My/93342 C IFW
Fig. 3 Measurement of single-track characteristics

and width. Also visible is a distortion of the groove, which has a magnitude of $\sim 0.5 \mu \mathrm{m}$. Here, an exact quantification of the depth $d_{i}$ cannot be made. The distortion may be a result of the sawing pre-treatment of the workpiece, which resulted in a rough surface, as visible in the section between the deep rolling grooves. This assumption can be backed up by the fact that the distortion decreases with increasing deep rolling pressure $p_{w}$. This can also be supported by the research of Denkena et al. [6], who reported a sufficient applicability of the roughness prediction for $Q_{d e f}>6.7$. This criterion is reached for $p_{w}=0.7 \mathrm{MPa}$.

Figure 3 also shows the image of the deep rolling ball with a diameter of $d_{b}=6.35 \mathrm{~mm}$. It should be noted that the axes are not equidistant which results in an elliptical representation of the crosscut spherical tool. It can be seen that the track generated by deep rolling represents the form of the tool, which was also observed by Denkena et al. [6] for deep rolling with turning-like kinematics. This observation also supports Mader's description of the deep rolling process [5] as a continuous sequence of embossing processes (see introduction). The resulting relationship between the deep rolling pressure $p_{w}$ and the indentation characteristics $d_{i}$ and $w_{i}$ is shown in Fig. 4. Here, the markers represent the medium of the three measurements and the error bar represents the upper and lower limits. It can be seen that both sizes are represented by logarithmic functions (Eqs. (1) and (2)). Here, a high agreement of $R^{2}>0.9$ could be achieved.

$w_{i}=273.03 \mu m \cdot \ln \left(p_{w}\right)+204.17 \mu m$

$d_{i}=3.162 \mu m \cdot \ln \left(p_{w}\right)+1.2965 \mu m$

With this description, the calculation of the theoretical roughness Rth can be performed according to Fig. 5. Here, the ball radius $d_{b} / 2$ and the lateral displacement $a_{b}$ are taken into account.
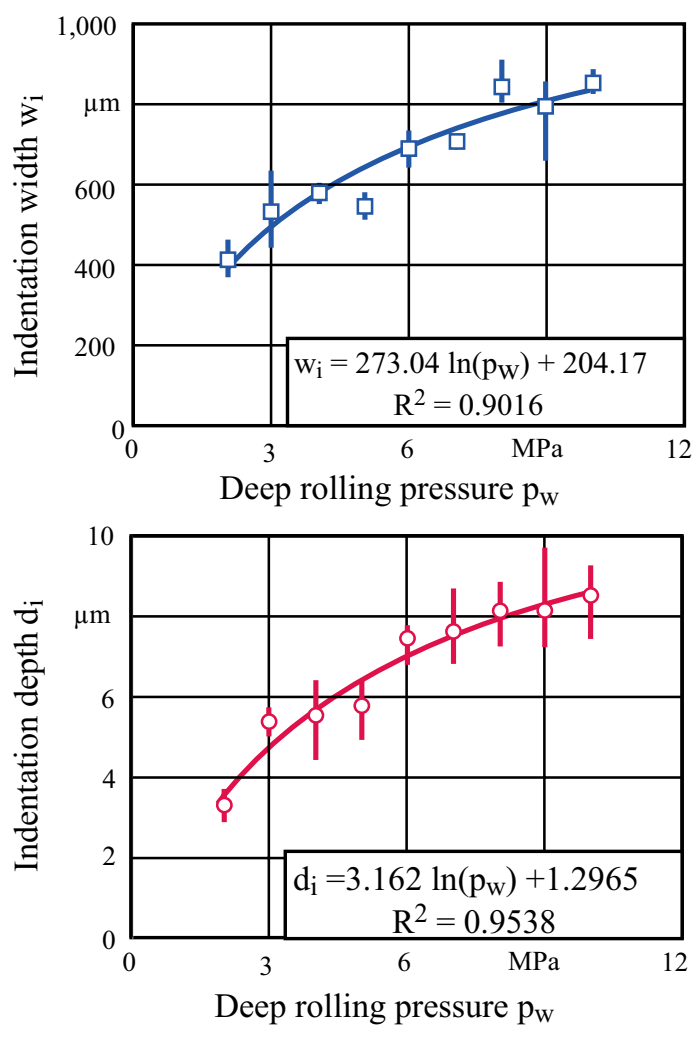

\begin{tabular}{llll}
\hline Deep Rolling: & & Tool: & Ecoroll HG6 \\
Single-Track & & Ball- $\varnothing:$ & $d_{b}=6.35 \mathrm{~mm}$ \\
Pressure: & $p_{\mathrm{w}}=$ var. & Material: & Ceramic \\
Lat. displacement: & $\mathrm{a}_{\mathrm{b}}=0$ & Workpiece: & AlSi10Mg \\
& & & My $/ 93341 \odot$ IFW
\end{tabular}

Fig. 4 Deep rolling pressure dependent indentation size

The calculation can be performed by

$R t h=\frac{d_{b}}{2}-h_{d}=\frac{d_{b}}{2}-\sqrt{\left(\frac{d_{b}}{2}\right)^{2}-\left(\frac{a_{b}}{2}\right)^{2}}$

with

$h_{d}=\sqrt{\left(\frac{d_{b}}{2}\right)^{2}-\left(\frac{a_{b}}{2}\right)^{2}}$

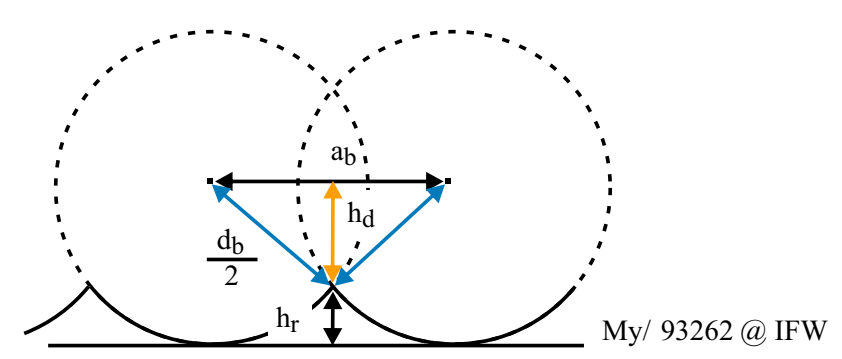

Fig. 5 Calculation of the theoretical roughness Rth 
For an accurate representation of the surface topography, the following boundary conditions have to be applied.

$a_{b} \leq w_{i}$

$R t h \leq d_{i}$

To investigate whether this description is accurate and to find limitations, the second set of experiments is performed under variation of the lateral displacement $a_{b}$ and the deep rolling pressure $p_{w}$. As described previously, the maximum deep rolling pressure generated by the used milling center is $p_{w}=8 \mathrm{MPa}$.

Therefore, $p_{w}$ is varied between $p_{w}=2$ and $8 \mathrm{MPa}$, because this experimental set is used for the setup of the usage of the new tool concept. Figure 6 shows tactile measurements of the resulting surfaces for $a_{b}=0.05$ and $a_{b}=0.11 \mathrm{~mm}$. The measurement is depicted in black, while the theoretical surface is red. In these measurements, the actual surface has no periodic structure. This periodicity is one of the basic principles of the model. One possible explanation for this deviation is, that the theoretic indentation is small in comparison to vibrations and the occurrence of build-ups. It can therefore be concluded that the model is neither applicable for the investigated deep rolling pressures $p_{w}$ nor for $a_{b}<0.11 \mathrm{~mm}$.

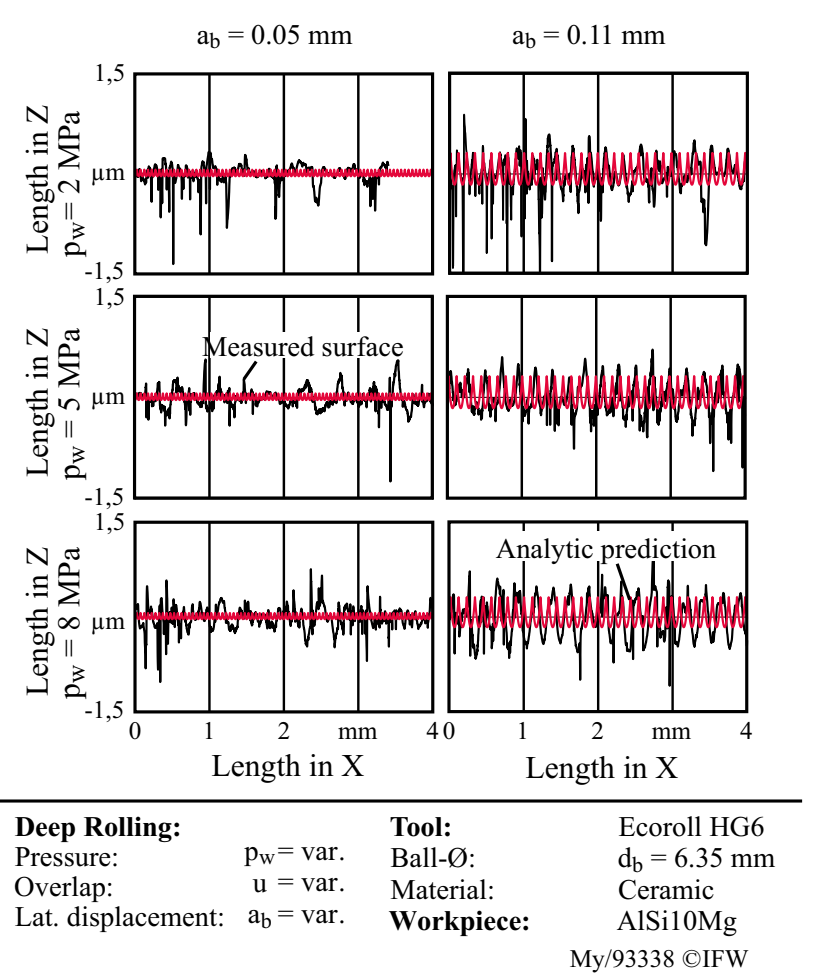

Fig. 6 Roughness profiles with low similarity to indentation profiles
Figure 7 shows the profiles of the surfaces generated with a lateral displacement $a_{b}=0.25,0.4$, and $0.5 \mathrm{~mm}$. In the upper row, the surfaces generated with the deep rolling pressure $p_{w}=2 \mathrm{MPa}$ are shown. For the lower displacements $a_{b}$, the periodic embossing of the deep rolling tool is clearly visible. It can be seen as well, that the grooves are distorted in a magnitude of $2 \mu \mathrm{m}$. The stress coefficient for this parameter combination is $Q_{\text {def }}=9.46$. The distortion contradicts the state of the art, where a distortion-free indentation is predicted for $Q_{\text {def }}>6.7$. Possible reasons for these differences can be the different plastic behavior of the cast AlSi10Mg in comparison to the materials investigated by Denkena et al. [6]. Another reason could lie in the different contact situation, where the resistance against material flow in both directions is lower. Another reason could be the initial roughness of the workpiece, which was comparatively high $(\mathrm{Rz}=15 \mu \mathrm{m})$. This results in higher necessary mechanical work for the full deformation. When machining with $p_{w}=2 \mathrm{MPa}$ and $a_{b}=0.5 \mathrm{~mm}$ the criteria defined in Eqs. (4) and (3) are not met, because the theoretical roughness is $\mathrm{Rth}=9.8 \mu \mathrm{m}$ and the groove depth is $d_{i}(2 \mathrm{MPa})=3.49 \mu \mathrm{m}$ according to Eq. (2). This means that the material is not deformed enough. Both criteria are fulfilled for $a_{b}=0.25 \mathrm{~mm}$ in combination with $p_{w}=5$ and 8 MPa. Here, a good representation of the actual profile can be performed using the analytical model. In comparison,
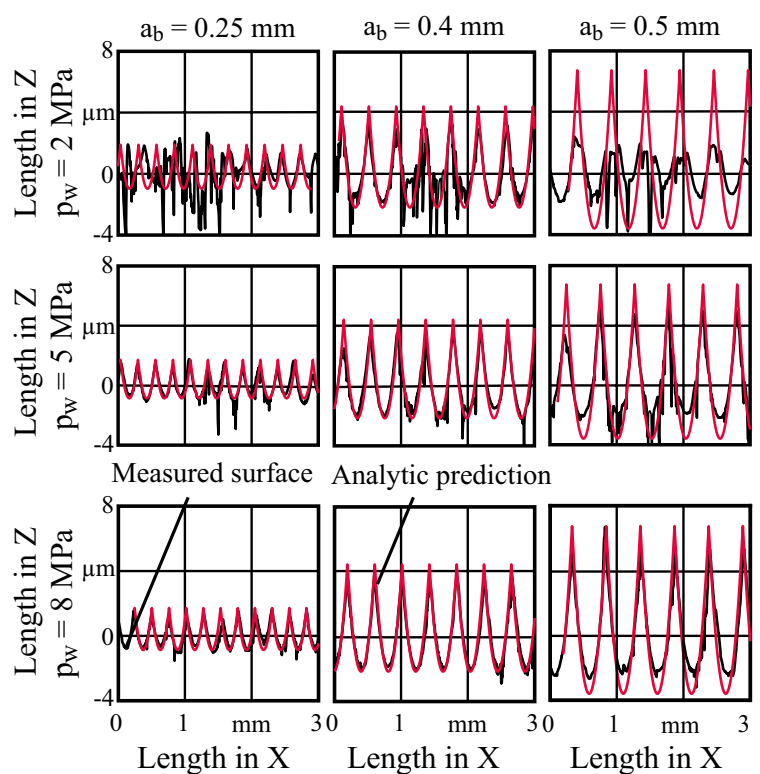

\begin{tabular}{lcll}
\hline Deep Rolling: & & Tool: & Ecoroll HG6 \\
Pressure: & $\mathrm{p}_{\mathrm{w}}=$ var. & Ball- $\varnothing:$ & $\mathrm{d}_{\mathrm{b}}=6.35 \mathrm{~mm}$ \\
Overlap: & $\mathrm{u}=$ var. & Material: & Ceramic \\
Lat. displacement: & $\mathrm{a}_{\mathrm{b}}=$ var. & Workpiece: & AlSi10Mg \\
& & & \\
& & & My/93339 CIFW
\end{tabular}

Fig. 7 Roughness profiles with higher similarity to indentation profiles 
the surface generated with $p_{w}=5 \mathrm{MPa}$ has a higher groove distortion, which can be explained by the lower deformation. The combination of $p_{w}=5 \mathrm{MPa}$ and $a_{b}=0.4 \mathrm{~mm}$ results in $\operatorname{Rth}(0.4 \mathrm{~mm})=6.4 \mu \mathrm{m}$ and $d_{i}(5 \mathrm{MPa})=6.39 \mu \mathrm{m}$. The criterion necessary for the applicability of the model from Eq. (6) is therefore not matched by a small fraction. However, the theoretic surface topography is well represented by this model. Therefore, this minimal difference can be neglected. A similar result is achieved when using $p_{w}=8 \mathrm{MPa}$. A lateral displacement of $a_{b}=0.5 \mathrm{~mm}$ results in a theoretical roughness of Rth $=9.8 \mu \mathrm{m}$. This exceeds the indentation depth $d_{i}(5 \mathrm{MPa})=6.39 \mu \mathrm{m}$ and $d_{i}(8 \mathrm{MPa})=7.87 \mu \mathrm{m}$. This is represented in both resulting surfaces. Using $p_{w}=5 \mathrm{MPa}$, a high groove distortion occurs, and the grooves and valleys do not reach the height of the theoretical surface. When applying $p_{w}=8 \mathrm{MPa}$, the grooves are smooth, but do not reach the sufficient depth. This behavior was prognosed by the application of Eq. (6). From this second set of experiments, the boundary conditions for the third experimental stage can be specified. The minimum pressure for a working prognosis was $p_{w, \min A l S i 10 \mathrm{Mg}}=5 \mathrm{MPa}\left(Q_{\text {def }}=12.8\right)$ and the prognosis worked for $a_{b, \min A l S i 10 \mathrm{Mg}}=0.25 \mathrm{~mm}$. It was also seen that the groove was less distorted with $p_{w}=8 \mathrm{MPa}$ $\left(Q_{\text {def }}=15\right)$. Therefore, the experiments using the novel tool approach are performed using $p_{w}=8 \mathrm{MPa}$. The kinematics and geometric dimensions of this tool are depicted in Fig. 2. The tool rotates around its vertical axis with a rotational speed $\mathrm{n}$ while performing straight horizontal movement with a velocity of $v_{f}$. The tool consists of two eccentric deep rolling balls. This results in two deep rolling operations in one full tool rotation. The process kinematic has a high similarity to a face milling process. Therefore, the mathematical relationships for such processes can be used with a replacement of the feed per tooth $f_{z}$ by the described feed per ball $f_{b}$. Based on these previous experiments and the process kinematics the process is expected to generate a surface with a cyclic peak distribution with a differing number of contacts depending on the rotational angle. The lowest number of contacts and therefore the highest roughness is expected to be in the direction of the feed velocity $v_{f}$. The left-hand image of Fig. 8 shows the resulting topography of a workpiece machined with the parameters specified in Sect. 2. It is visible that the topography generally follows the tool path (see Fig. 2). The peak distance is, as expected, lower at a higher rotational angle. This can be explained by the higher number of contacts. The profile obtained from the feed velocity axis of the machined surface is depicted the upper right hand side of Fig. 8. It can be seen that the surface consists of a periodic sequence of spheric indentations. This profile shows optical similarity to the surfaces generated in the second experimental section. The distance between the peaks is $d_{p}=0.5 \mathrm{~mm}$, which is twice the feed per ball $f_{b}$. The lower right side of Fig. 8 shows a
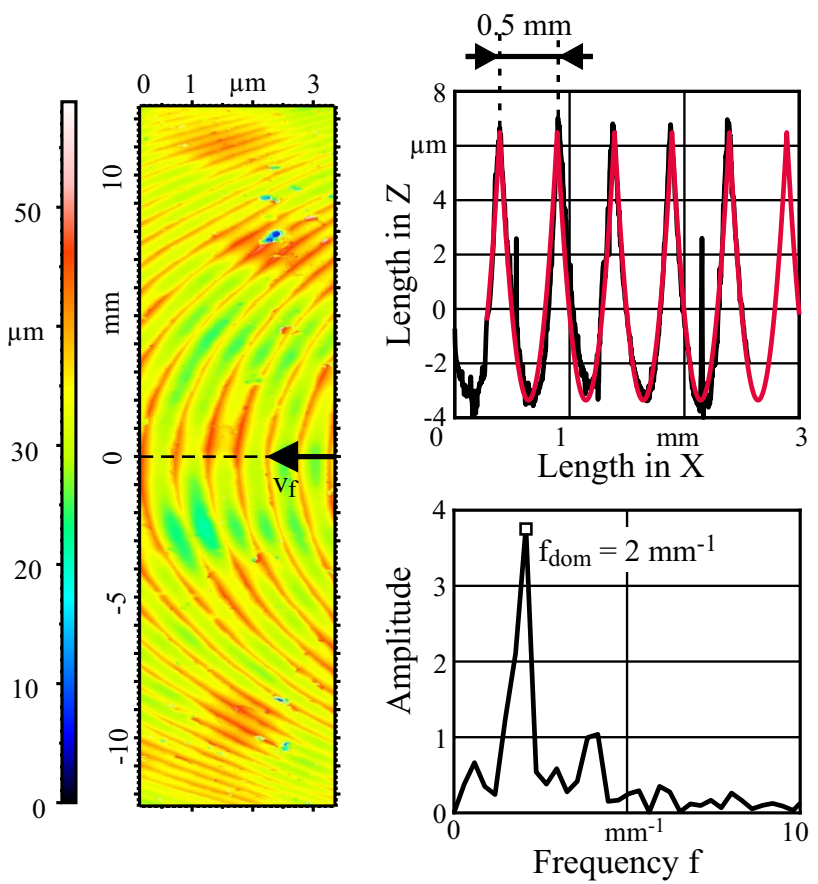

\begin{tabular}{|c|c|c|c|}
\hline $\begin{array}{l}\text { Deep Rolling: } \\
\text { Milling kinematic }\end{array}$ & & $\begin{array}{l}\text { Tool: } \\
\text { Ball-Ø: }\end{array}$ & $\begin{array}{l}\text { Ecoroll HG6 } \\
\mathrm{d}_{\mathrm{b}}=6.35 \mathrm{~mm}\end{array}$ \\
\hline Pressure: & $\mathrm{p}_{\mathrm{w}}=8 \mathrm{MPa}$ & Material: & Ceramic \\
\hline $\begin{array}{l}\text { Feed velocity: } \\
\text { Rotational speed: }\end{array}$ & $\begin{array}{l}\mathrm{v}_{\mathrm{f}}=25 \mathrm{~mm} / \mathrm{mi1} \\
\mathrm{n}=50 \mathrm{~min}^{-1}\end{array}$ & Workpiece: & AlSi10Mg \\
\hline Feed per ball: & $\mathrm{f}_{\mathrm{b}}=0.25 \mathrm{~mm}$ & & $\mathrm{y} / 93344$ (c) IFW \\
\hline
\end{tabular}

Fig. 8 Surface topography using the milling-kinematic tool

Fast Fourier Transformation (FFT) of the profile. Here it is shown that the dominant frequency is $f_{\text {dom }}=2 \mathrm{~mm}^{-1}$. This contradicts the measured distance $d_{p}$. As visible in Fig. 2, the ball distance which should be expected is the feed perball $f_{b}$, which would reduce the peak height and therefore the roughness.

One possible explanation lies in one main principle of deformation processes: Volume constancy. In opposition to a cutting process, the material is not removed. Because the indentation width is $w_{i}(8 \mathrm{MPa})>800 \mu \mathrm{m}$ and the feed per ball $f_{b}$ is significantly smaller, a new deformation of the groove generated by the first deep rolling ball is generated. Therefore, the benefits of this new tool concept are slightly diminished. To validate this, a higher number of experiments under variation of the process parameters (rotational speed $\mathrm{n}$, feed per ball $f_{b}$ ) should be performed.

\section{Discussion}

This paper discusses approaches for deep rolling of flat and free form workpieces using hydrostatic deep rolling tools with spherical rolling elements with the goal to 
describe the resulting roughness. Because deep rolling of flat workpieces with conventional tools would take a comparatively long machining time, a new tool design which utilizes milling kinematics was introduced. To describe the resulting topography after using this approach, three experimental stages were performed. In the first stage, single-track experiments under variation of the deep rolling pressure $p_{w}$ were carried out. The experiments resulted in a description of the indentation depth $d_{i}$ and width $w_{i}$. The second stage contained sequential deep rolling experiments under the variation of the lateral displacement $a_{b}$ and the deep rolling pressure $p_{w}$. These experiments defined boundary conditions for a description of the surface using a geometrical approach. The geometric description was applicable for lateral displacements of $a_{b} \geq 0.25 \mathrm{~mm}$ and deep rolling pressures of $p_{w}>5$ $\mathrm{MPa}$. Under knowledge of these boundary conditions, the new tool was used with a feed per ball $f_{b}=0.25 \mathrm{~mm}$ and a deep rolling pressure $p_{w}=8 \mathrm{MPa}$. Despite having the same process kinematics as face milling, the peak to peak distance in center of feed velocity direction was $d_{p}$ $=0.5 \mathrm{~mm}=2 f_{b}$. A possible explanation is based on the different deformation behavior in comparison to cutting mechanisms. It was also shown that the tool offers the possibility to reduce the machining time for flat and freeform workpieces, while the resulting surface topography could be described by an alignment of spheres for one full rotation. For future applications and research, the forming behavior should be considered. Knowledge of the forming behavior could be achieved using a finite element simulation. Besides topography, the resulting surface integrity components such as the residual stress state are unclear and should be investigated in the future. The tool concept itself should be improved for future industrial application. While the deep rolling pressure $p_{w}$ was provided by the coolant compressor of the Heller H5000, $p_{w}=8 \mathrm{MPa}$ is a comparably low rolling pressure regarding most deep rolling applications. To enhance the applicability of the tool concept to machine materials with higher mechanical strengths, a rotary hydraulic joint could be applied to the shaft. Here, the necessary mechanical load ( $p_{w}>40 \mathrm{MPa}$ ) could be applied to machine even quenched materials. The tool design should be improved regarding the overhang length of the deep rolling elements. Using the standard tools, only low rotational speeds $n$ could be used because of the risk of high torque generated by the rolling forces. A customized, shorter version could reduce this risk.

Funding Open Access funding enabled and organized by Projekt DEAL. This research was funded by the Federal Ministry of Economics and Energy (BMWi) via the German Federation of Industrial Research Associations (AiF) e. V., Grant Number IGF-20626 N/1.

\section{Compliance with ethical standards}

Conflict of interest The authors declare no conflict of interest. The funders had no role in the design of the study; in the collection, analyses, or interpretation of data; in the writing of the manuscript, or in the decision to publish the results.

Open Access This article is licensed under a Creative Commons Attribution 4.0 International License, which permits use, sharing, adaptation, distribution and reproduction in any medium or format, as long as you give appropriate credit to the original author(s) and the source, provide a link to the Creative Commons licence, and indicate if changes were made. The images or other third party material in this article are included in the article's Creative Commons licence, unless indicated otherwise in a credit line to the material. If material is not included in the article's Creative Commons licence and your intended use is not permitted by statutory regulation or exceeds the permitted use, you will need to obtain permission directly from the copyright holder. To view a copy of this licence, visit http://creativecommons.org/licenses/by/4.0/.

\section{References}

1. Abrão AM, Denkena B, Breidenstein B, Mörke T (2014) Surface and subsurface alterations induced by deep rolling of hardened AISI 1060 steel. Prod Eng Res Devel 8:551-558. https://doi. org/10.1007/s11740-014-0539-x

2. Courbon C, Valiorgue F, Claudin C, Jacquier M, Dumont F, Rech J (2016) Influence of some superfinishing processes on surface integrity in automotive industry. Procedia CIRP 45:99-102

3. Meyer D, Brinksmeier E, Hoffmann F (2011) Surface hardening by cryogenic deep rolling. Procedia Eng 19:258-263. https://doi. org/10.1016/j.proeng.2011.11.109

4. Schuh A, Zeller C, Holzwarth U, Kachler W, Wilcke G, Zeiler G, Eigenmann B, Bigoney J (2007) Deep rolling of titanium rods for application in modular total hip arthroplasty. J Biomed Mater Res 81:330-335. https://doi.org/10.1002/jbm.b.30669

5. Mader S (2006) Festwalzen von Fan- und Verdichterschaufeln. Dr.-Ing Dissertation, RWTH Aachen

6. Denkena B, Abrão A, Krödel A, Meyer K (2020) Analytic roughness prediction by deep rolling. Prod Eng Res Dev. https://doi. org/10.1007/s11740-020-00961-0

7. Grzesik W, Zak K, (2012) Modification of surface finish produced by hard turning using superfinishing and burnishing operations. J Mater Proc Tech 212:315-322. https://doi.org/10.1016/j.jmatp rotec.2011.09.017

8. Bouzid W, Tsoumarev O, Sa K (2003) An investigation of surface roughness of burnished AISI 1042 steel. Int J Adv Manuf Tech 24:120-125. https://doi.org/10.1007/s00170-003-1761-4

9. Yuan XL, Sun YW, Gao LS, Jiang SL (2016) Effect of roller burnishing process parameters on the surface roughness and microhardness for TA2 alloy. Int J Adv Manuf Technol 85:1373-1383. https://doi.org/10.1007/s00170-015-8031-0

10. Feldmann GG (2012) Verbesserte mechanische Oberflächenverfestigung von Schaufeln an integral beschaufelten Hochdruckverdichterrotoren. Dr.-Ing. Diss, Aachen

11. DIN EN 1706:2020-06 (2020) Aluminium and aluminium alloysCastings-chemical composition and mechanical properties. Beuth Verlag GmbH, Berlin

12. Johnson KL (2003) Contact mechanics, 9th edn. Cambridge Univ. Press, Cambridge

Publisher's Note Springer Nature remains neutral with regard to jurisdictional claims in published maps and institutional affiliations. 